
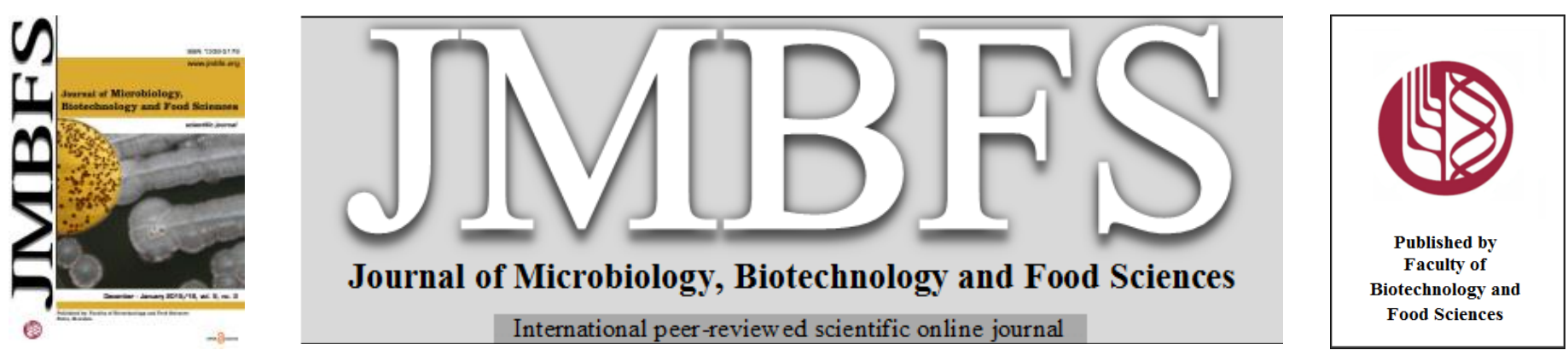

\title{
PHYSICOCHEMICAL AND RHEOLOGICAL PROPERTIES OF DOOGH UNDER SPECIFIC FERMENTATION
}

\author{
Babak Pakbin ${ }^{1}$, Razzagh Mahmoudi $*^{2}$, Omid Fakhri ${ }^{3}$
}

Address(es): Dr. Razzagh Mahmoudi,

${ }^{1}$ University of Tehran, Faculty of Veterinary Medicine, Department of Food Hygiene and Quality Control, Tehran, Iran.

${ }^{2}$ Qazvin University of Medical Sciences, School of Health, Department of Food Hygiene and Safety, Qazvin, Iran.

${ }^{3}$ Asia-Pacific center for animal health, Faculty of veterinary and agricultural science, the University of Melborn, Parkville, Victoria 3010, Australia.

*Corresponding author: r.mahmodi@yahoo.com

doi: 10.15414/jmbfs.2015/16.5.3.238-242

\section{ARTICLE INFO}

Received 18. 2. 2015

Revised 15. 3. 2015

Accepted 27.9. 2015

Published 1. 12. 2015

Regular article

OPEN OACCESS

\begin{abstract}
Fermented dairy products such as doogh are more nutritious than the natural milk from which they are made. In this study enhancing the viscosity of Doogh (Iranian yogurt drink) fermented by Leuconostoc mesenteroides under the optimum condition of exopolysaccharide (EPS) production including temperature of $25^{\circ} \mathrm{C}$, agitation of $120 \mathrm{RPM}$ and different sucrose contents from 0 to $2 \%$, $\mathrm{w} / \mathrm{w}$, was investigated. Addition of sucrose was not influenced the rheological and sensory characteristics of Doogh samples before the fermentation significantly according to sensory and rheological analysis. The results of chemical, microbiological, viscosity, serum separation and sensory analysis showed that viscosity of Doogh increased corresponding to sucrose contents during the fermentation up to $10.01 \mathrm{cp}$ with no change in the taste of the Doogh samples. Also, sensory analysis of consistency confirmed the viscosity results. Serum separation values of samples also showed enhancement in stability after the fermentation and finally, this special fermentation process contributed to enhancement in viscosity of Doogh as an edible suspension, with reasonable economic targets compared with other stabilizing methods.
\end{abstract}

Keywords: Doogh, fermentation, Leuconostoc mesenteroides, physicochemical quality, rheological properties

\section{INTRODUCTION}

Dairy drinks are a group of dairy products that have been known as acidified dairy drink (ADD) and produced variously, e.g. yogurt drink, buttermilk, whey drink, kefir, etc. These dairy products can be described as an acidified protein liquid system with lactic acid fermentation by lactic acid bacteria (LAB) with stability occasionally similar to natural milk (Laurent and Boulenguer, 2003). Yogurt, by its presence in the market and high consumption is the most important fermented dairy product (Ramírez-Sucre and Vélez-Ruiz, 2013) Also, the number of consumers of yogurt drinks and associated products increased in recent years (Gonzalez et al., 2011). Yogurt drinks are produced and consumed in various ways in the world. Doogh is a traditional Iranian yogurt drink usually is manufactured by mixing of water, salt, set or stirred yogurt and extract of some aromatic herbs (Azarikia and Abbasi, 2010). Ayran also is another traditional yogurt drink with high fat content that is produced and consumed in Turkey (Koksoy and Kilic, 2004). It has been reported that the fermented dairy products are more nutritious than the natural milk from which they are made. Importance of nutritional value in these products attributes to availability of certain nutrients ( $\mathrm{O}^{\prime}$ Connell and Fox, 2001) and hydrolysis of milk constituents with fermentation by LAB making them more digestible (Park, 1994). Yogurt and yogurt drink through being more digestible caused by lactic acid fermentation (Gonzalez $\boldsymbol{e t}$ al., 2011), are enriched with bioactive peptides that are produced by proteolytic activity (Kunda $\boldsymbol{e t}$ al., 2012) and the presence of LAB having functionality properties known as probiotic organisms (RuasMadiedo et al., 2002)

Yogurt drinks are produced from natural milk by lactic acid fermentation. Casein in milk at its natural pH of approximately 6.6 is in a stable form, micelle. When the $\mathrm{pH}$ of milk is decreased by lactic acid fermentation or other acidification process to $5.5-5.8$, zeta potential decreases conducting the micelles to form clusters. During producing of lactic acid and lowering the $\mathrm{pH}$ to 5 micelles in clusters are in multi-strands structure. This position leads clusters to aggregation by more decreasing of $\mathrm{pH}$ to below the $\mathrm{pH} 5$. These steps occur to construct suspension form of casein from its colloidal system in yogurt and yogurt drink under condition of decline in $\mathrm{pH}$ by lactic acid (Laurent and Boulenguer, 2003). Biochemical pathways in yogurt fermentation include carbohydrate, protein, fat and vitamins metabolic activities that their final products are lactic acid; peptides and amino acids; free fatty acids and vitamins of group B, respectively. Moreover, metabolism of carbohydrate (lactose) and produced lactic acid is the most important biochemical reaction (O'Connell and Fox, 2001) Lactic acid fermentation can cause biochemical changes in the milk. It reduces the $\mathrm{pH}$ of the milk and leads to a progressive being soluble of micellar calcium phosphate, causing the demineralization of casein micelles and their destabilization, which generates the complete precipitation of casein in a $\mathrm{pH}$ range of 4.6-4.7. Also, produced lactic acid by LAB provides the yogurt or yogurt drink with its shape, acid taste and contributes to the flavor (Santos et al. 2000). Lactic acid is the most important product of $L A B$ while the fermentation time increases in any substrate that this kind of fermentation has been done with it.

Despite lactic acid producing, $\mathrm{LAB}$ constructs some other fermentation products that significantly are produced by them. One group of these secondary metabolites is hetero polysaccharides, such as hydrocolloid materials, produced by some varieties of LAB; for example leuconostoc and some of the lactobacillus strains. The hetero polysaccharides that are secreted by LAB have been known as EPS (Johanningsmeier et al., 2007). EPS develops the texture, modifies the rheological properties and hence the stability of the products by increase in viscosity (Huang et al., 2013). EPS incorporate with casein when it is continuous to influence, increase the viscosity and decline the serum separation of suspension system (Kiani et al., 2010). The natural properties of milk protein in acidified condition are extensive casein micelle aggregation, sedimentation and subsequent macroscopic whey separation. It is well known that the stabilization of acidified milk drinks is dependent upon many factors including $\mathrm{pH}$ range, protein content, hetero polysaccharides etc. The presence of hetero polysaccharides improves the viscosity, serum separation and stability of the suspension system of acidified milk drinks significantly more than other factors. Consequently, addition of natural and microbial hetero polysaccharides is used in manufacturing acidified milk drinks such as yogurt drinks as a stabilization method (Thi and Ipsen, 2009). Doogh, the Iranian yogurt drink also is an edible suspension that its stability is developed by this method (Kiani et al., 2010).

Despite adding stabilizers, for increasing viscosity and declining serum separation to enhance the stability of suspension system, other methods specially are used to achieve viscosity development such as fermentation with specific microorganisms under characterized conditions (Edema, 2010). Increased the viscosity of formulated microbial culture by fermentation with Streptococcus thermophilus under developed condition of EPS producing was reported (Shene 
et al. 2008). Also enhance the viscosity of sour maize meal was made by fermentation with Leuconostoc mesenteroides (Edema, 2010). EPS produce bacteria are used to increase the viscosity and stability of fermented materials. Lactobacilluslactis, raftinolactis and gravieae; Leuconostoc pseuduplantarum and mesenteroides are the lactic acid bacteria that can secrete -EPS or some other associated hydrocolloid materials and also develop the viscosity serum separation and stability of the suspensions during and after the fermentation (Adebayo-tayo and Onilude, 2008). In addition to these technological benefits, EPS have beneficial physiological effects on the consumer. It is assumed that, enhancement of viscosity in EPS containing foods may increase the residence time of ingested fermented milk in the gastrointestinal tract and therefore be beneficial to a transient colonization by probiotic bacteria as a functional product (Hemme and Foucaud-Scheunemann, 2004)

Leuconostoc represent a small percentage of the mesophilic micro-flora belonging to the group of LAB including a wide range of varieties that are well known in the dairy industry and functional foods (Kekkonen et al., 2008). L. mesenteroides between varieties of Leuconostoc has the highest efficiency in EPS producing. Strains of these bacteria that efficiently produce EPS include B-1355, B1498, B-1299 and B-1501 (Naessens et al., 2005). EPS produced by $L$. mesenteroides, has been secreted in a higher efficiency under best temperature and agitation conditions that are about $25^{\circ} \mathrm{C}$ and 120 RPM, Respectively (Johanningsmeier et al., 2007). These conditions lead EPS better to be contributed in fluidal media that bacterium is growing in it. In this research enhancement in viscosity of Iranian yogurt drink (Doogh) by fermentation with L. mesenteroides strain of B-1501 was investigated. Manufactured Doogh has fermented by $L$. mesenteroidesas mentioned above under the best cultural conditions of EPS producing that are temperature $25^{\circ} \mathrm{C}$, agitation $120 \mathrm{RPM}$ and the presence of different contents of sucrose (Edema, 2010). Viscosity, serum separation, consistency and stability of Doogh samples were studied during the fermentation time.

\section{MATERIALS}

Pasteurized Doogh (pH: 4.3, Fat: 1.2\%) and commercial sugar that were used for this study were purchased from the local market in Karaj, Iran. Packages were stored at $4^{\circ} \mathrm{C}$ until the refermentation and experiments; finally was divided into $200 \mathrm{ml}$ containers for incubation by L. mesenteroides B-1501 and sampling for chemical, microbiological, rheological and sensory analysis, consequently.

\section{METHODS}

\section{Fermentation of $\mathrm{Doogh}$}

Preparation of L. mesenteroidesstocks for refermentation of Doogh samples

The activation of $L$. mesenteroideshas been done by the procedure described by Santos et al. (2000). The L. mesenteroides B-1501 (Deutsche sammlung von Mikroorganismen und Zellkulturen GmbH., Germany) was supplied for this study obtained from microbial culture stock of 'Department of Food Science and Engineering` (University of Tehran). Bacterial culture was stored frozen at $-20^{\circ} \mathrm{C}$ in MRS medium (Merck., Germany) containing 20\% glycerol. The strain has activated by incubation at $30^{\circ} \mathrm{C}$ for 24 hours in ten milliliters of MRS broth (dextrose $20.0 \mathrm{~g} / \mathrm{L}$; meat peptone $10.0 \mathrm{~g} / \mathrm{L}$; beef extract $10.0 \mathrm{~g} / \mathrm{L}$; yeast extract $5.0 \mathrm{~g} / \mathrm{L}$; sodium acetate $5.0 \mathrm{~g} / \mathrm{L}$; disodium phosphate $2.0 \mathrm{~g} / \mathrm{L}$; ammonium citrate $2.0 \mathrm{~g} / \mathrm{L}$; tween $801.0 \mathrm{~g} / \mathrm{L}$; magnesium sulfate $0.1 \mathrm{~g} / \mathrm{L}$, manganese sulfate 0.05 $\mathrm{g} / \mathrm{L}$ ). These stocks were grown for being appropriate for fermentation and EPS producing in Doogh substrate.

\section{Fermentation process of Doogh samples}

Fermentation experiments were conducted in test container, each containing 200 $\mathrm{mL}$ of Doogh yogurt drink. Sugar was added into Doogh containers in 0, 0.5, 1 , 1.5 and $2 \% \mathrm{~W} / \mathrm{W}$. Adding these contents of suger have not made any significant different in initial Doogh samples (similar viscosity compared with the blank sample before fermentation). All containers were inoculated with 24-h activated culture in $5 \% \mathrm{~V} / \mathrm{V}$ and incubated at $25^{\circ} \mathrm{C}$ and agitation of $120 \mathrm{RPM}$, which are the best temperature and agitation conditions to EPS producing by $L$ mesenteroides, for 72 hours fermentation (Naessens et al., 2005). All samples were taken from the containers at the times $0,24,48$, and 72 has the fermentation time increases.

\section{Chemical properties}

Titrable acidity (TA, g lactic acid in $100 \mathrm{~g}$ of sample), was measured for all samples, using $0.1 \mathrm{~mol} \mathrm{~L}^{-1}-\mathrm{NaOH}$ (sodium hydroxide) and10 g $\mathrm{L}^{-1}$ phenolphthalein (Scharlau Co, Spain)solution in $950 \mathrm{~mL} \mathrm{~L}^{-1}$ ethanol as an endpoint indicator. In short, $1 \mathrm{~mL}$ of sample was diluted with $9 \mathrm{~mL}$ distilled water and titratedagainst $\mathrm{NaOH}$ (Gonzalez et al., 2011). The $\mathrm{pH}$ of the samples was alsodetermined by using a $\mathrm{pH}$-meter (Methrohm 744, Netherland).

\section{Microbiological analysis}

Microbiological analysis of this investigation includes measurement of cell growth in sampling times. Cell growth was measured by plating on MRS agar medium (Merck, Germany) and incubating anaerobically at $30^{\circ} \mathrm{C}$ for $48 \mathrm{~h}$ (Edema, 2010). The Initial lactic acid microbial population of Doogh samples before fermentation with activated $L$. mesenteroides was $2.17 \log \mathrm{CFU} \mathrm{g}^{-1}$.

\section{Viscosity of Doogh samples}

According to the method of Azarikia and Abbasi (2010) the dynamic viscosity of each sample was measured by using a rotational viscometer (DV-III digita viscometer; Brookfield RVT, USA). All measurements were done at room temperature $\left(24 \pm 1{ }^{\circ} \mathrm{C}\right)$ using coaxial cylinder geometry on a small sample adapter and an SC4-29 spindle set at $24 \mathrm{rpm}$ (Calibrated with distilled water at the same temperature of experiment in the viscosity of $1 \mathrm{cp}$ ). Viscosity was recorded in cp. The viscosity of initial Doogh without any fermentation and adding sugar was $2.49 \mathrm{cp}$; without any fermentation and with adding $2 \% \mathrm{~W} / \mathrm{W}$ sugar was measured $2.57 \mathrm{cp}$, whose difference is insignificance.

\section{Serum separation of $\mathrm{Doogh}$}

Doogh samples were placed in50 $\mathrm{ml}$ graduated cylinders $(1.2 \mathrm{~cm}$ radius, $12.5 \mathrm{~cm}$ height, and $1 \mathrm{ml}=0.25 \mathrm{~cm}$ ) and stored at $4^{\circ} \mathrm{C}$. The volume of separated serum at the top was read after storage for 15 days. Serum separation measured according to the method of Azarikia and Abbasi (2010).

\section{Sensory analysis of Doogh samples}

Doogh samples were analyzed for taste, consistency and overall acceptability after the 72-hour fermentation. Sensory analysis was performed by using 20 panelists familiar with the product. A 7-point hedonic scale including both the number and verbal scores was provided to the panelists (Koksoy and Kilik, 2003). The scores were; Like extremely (7), Like very much (6), Like moderately (5), Neither like nor dislike (4), Dislike moderately (3), Dislike very much (2), Dislike extremely (1). A section for the panelist's comment was presented in the evaluation sheet. Consistency is associated to the viscosity perceived by the panelists. Mean scores for each attribute were calculated for comparison of the samples.

\section{Statistical analysis}

All determinations were made in triplicate trials and the data generated in sensory analysis and were subjected to the one-way analysis of variance (ANOVA) at 5\% level of significance using Minitab statistical software (V16, Minitab Inc., Pennsylvania, USA). Also, means were separated by Duncan`s multiple range tests.

\section{RESULTS AND DISCUSSION}

In this study we applied the fermentation with L. mesenteroides in Doogh samples to change the rheological and physicochemical property of drinks. Via measurement of viscosity and serum separation, changes in stability can be investigated during and after the fermentation. Sensory analyses such as taste and consistency evaluation of fermented samples were associated with $\mathrm{pH}$, acidity and viscosity variations as the fermentation time increased (Koksoy and Kilic, 2004).

\section{pH and titrable acidity changes in Doogh samples}

Chemical characteristics of the substrate during fermentation period significantly changed, because the during fermentation process the bacteria is active because of the activity of organisms, existed in the fermentation process. These changes indicate the growth and activity of the organism during the fermentation. Organic acids such as lactic, citric, propionic and acetic acid are produced by fermentative micro-organisms. These products considering their ionization constant are the most important factors that influence the final $\mathrm{pH}$ of fermentation products. $\mathrm{pH}$ and titrable acidity have shown the reverse correlation; increase in organic acid content and decline in $\mathrm{pH}$ value (Sefa-dedeh et al., 2003). Fermentation of Doogh with $L$. mesenteroides contributed to the reduction of the $\mathrm{pH}$ in all samples with fermentation time that has been shown in Fig 1. The $\mathrm{pH}$ of the samples after the fermentation varied from 3.81 to 4.05 and the initial $\mathrm{pH}$ of Doogh without fermentation was measured 4.45 . Fermentation by this organism leads to decrease in $\mathrm{pH}$ significantly in dairy and nondairy substrates because of production of lactic acid predominantly and some other organic acids inconsiderably that also produced ordinarily by other LAB as the fermentation time increases (Sefa-dedeh et al., 2003). Production of lactic acid is contributed to enhancement of titrable acidity as it has shown in Fig 2. The initial acidity of Doogh sample without any fermentative treatment was measured $0.61 \% \mathrm{w} / \mathrm{w}$ lactic acid that increased after the fermentation; moreover titrable acidity of the 
samples varied from 0.72 to $0.83 \%$ w/w lactic acid. Lactic acid in addition to have anti-pathogenic characteristics, influence the taste of the dairy and nondairy fermented drinks (Kiani $\boldsymbol{e t}$ al., 2010). Range of changes in titrable acidity is the critical fact that determines the significant difference in taste of the fermented drinks (Balaswamy et al., 2011). The relationship between titrable acidity and taste of the fermented samples has discussed in sensory analysis section of this study. It should be noted that the importance of $\mathrm{pH}$ and titrable acidity in this investigation is for demonstration of microbial activity and growth during the fermentation process under the condition of sugar existence that leads to some special effects. Gonzalez et al (2011) have shown drop in $\mathrm{pH}$ and enhancement of titrable acidity or production of organic acids show the activity and growth of fermentative organism in substrate. For this reason, it should be resulted that $L$ mesenteroides have fermented the substrate (Doogh) after $72 \mathrm{~h}$ and it was confirmed by investigation of cell growth.

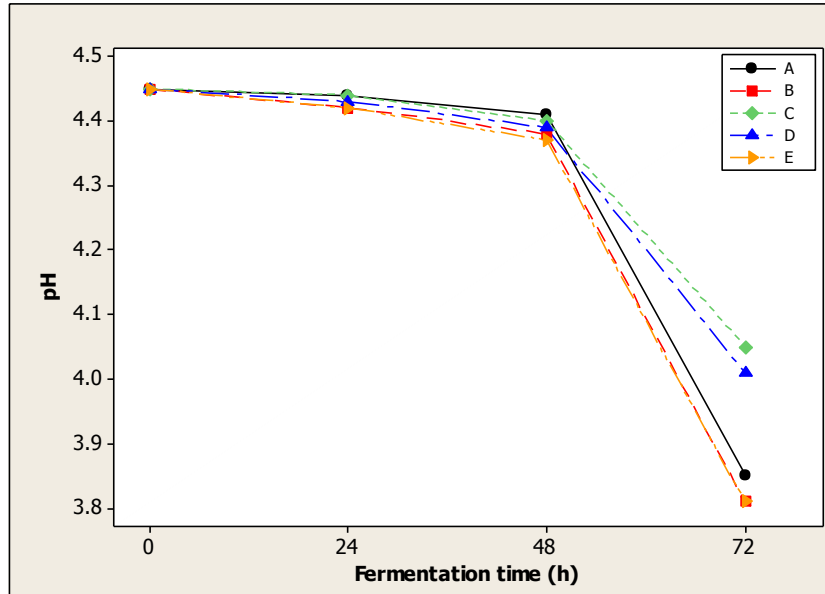

Figure $1 \mathrm{pH}$ changes during fermentation of Doogh samples with $L$ mesenteroides under the optimum conditions of EPS producing, containing sugar contents of $\mathrm{A}=0 \%, \mathrm{~B}=0.5 \%, \mathrm{C}=1 \%, \mathrm{D}=1.5 \%$ and $\mathrm{E}=2 \%(\mathrm{~W} / \mathrm{W})$

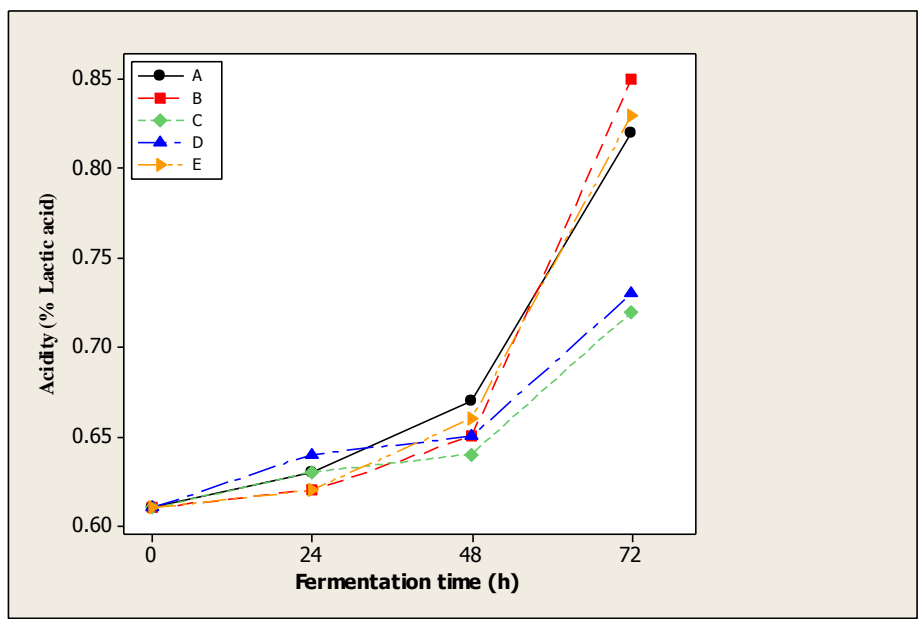

Figure 2 Titrable acidity variations during fermentation of Doogh samples with L. mesenteroides under the optimum conditions of EPS producing, containing sugar contents of $\mathrm{A}=0 \%, \mathrm{~B}=0.5 \%, \mathrm{C}=1 \%, \mathrm{D}=1.5 \%$ and $\mathrm{E}=2 \%(\mathrm{~W} / \mathrm{W})$

\section{Microbiological analysis of Doogh samples}

In this study fermentation of Doogh with Leuconostochas progressed under the optimum conditions of EPS producing that are contributed to viscosity development after the fermentation. These constant conditions include temperature of $25^{\circ} \mathrm{C}$ and agitation of 120 RPM. Analysis of variables in this experimental investigation demonstrates that the fermentation process is running well so it has considered as an indication of progression in this bioprocess (Shene et al., 2008). Fig 3 shows the microbial count of L. mesenteroidesduring the fermentation of Doogh samples. The initial microbial count of Doogh (after the inclusion with L.mesenteroides) was measured $4.50 \log \mathrm{CFU} \mathrm{ml}{ }^{-1}$ that after $72 \mathrm{~h}$ fermentation has increased to $6 \log \mathrm{CFU} \mathrm{ml}{ }^{-1}$. This enhancement causes the changes of $\mathrm{pH}$ and acidity that mentioned before. Acidity and $\mathrm{pH}$ variations are relevant to microbial count, but at all no significant difference are there between the different sugar contents of samples that shows existence of sugar have not influenced the growth of Leuconostoc (Santos et al., 2000).

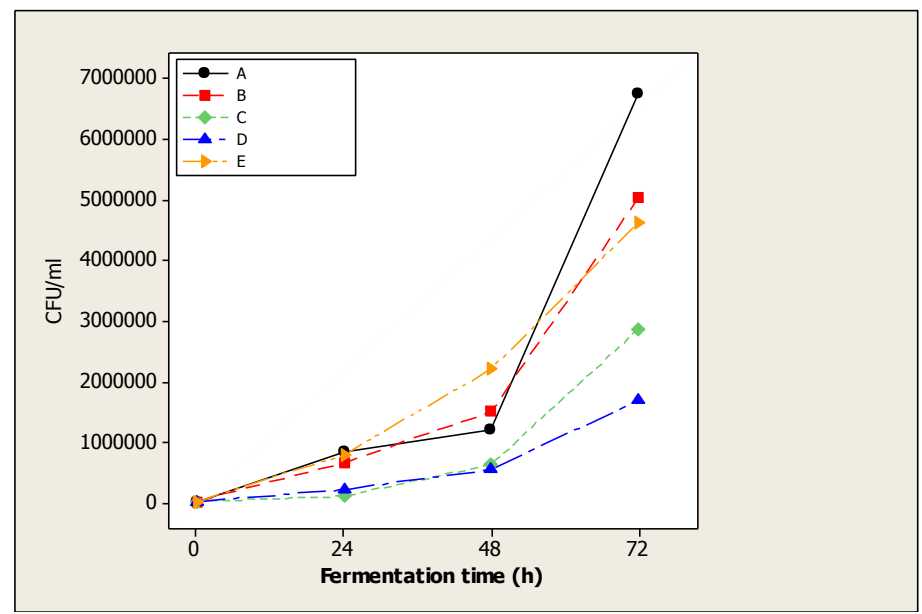

Figure 3 Microbial count of L.mesenteroides during fermentation of Doogh samples under the optimum conditions of EPS producing, containing sugar contents of $\mathrm{A}=0 \%, \mathrm{~B}=0.5 \%, \mathrm{C}=1 \%, \mathrm{D}=1.5 \%$ and $\mathrm{E}=2 \%(\mathrm{~W} / \mathrm{W})$

\section{Viscosity of Doogh samples}

Indeed enhancement in viscosity of Doogh samples is the final goal of this investigation so it has shown in Fig 4, the viscosity of samples has increased during the progress of fermentation. As it is obvious in Fig 4 the sample without sugar did not show any significant difference in measured viscosity during and after the fermentation however in samples containing sugar, related to content of sugar in samples, the viscosity is considerably enhanced during 72-h fermentation and it has reached to $10.01 \mathrm{cp}$. L. mesenteroides produces EPS under the optimum conditions that are implemented in this fermentation; also this polysaccharide enhances the viscosity of Doogh by standing between yogurt drink particles are known the suspension casein and adsorbing water. Agitation also contributes to distribution of EPS through the substrate particles (Santos $\boldsymbol{e t}$ al., 2000). By the progress of fermentation during 72 hours, EPS producing and viscosity of samples was intensified gradually. Ordinarily, the premier source of EPS that is produced by $L$. mesenteroides is sugar that metabolize to homopolysaccharides (Santos et al., 2000); therefore it is reasonable that viscosity of samples should be increased according to their sugar contents after and while the bioprocess time increases.

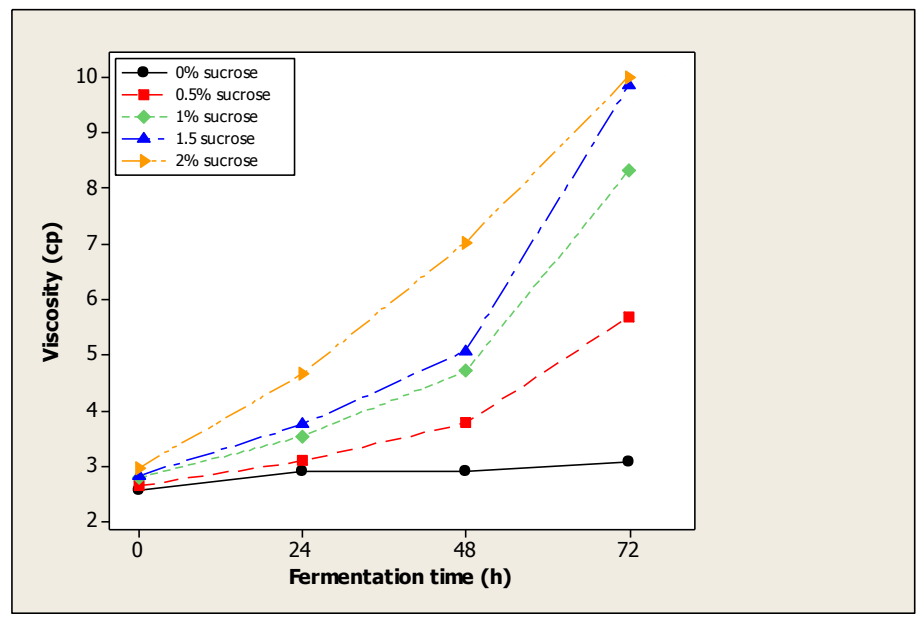

Figure 4 Viscosity changes (cp) of Doogh samples during fermentation with $L$ mesenteroides under the optimum conditions of EPS producing, containing sugar contents of $\mathrm{A}=0 \%, \mathrm{~B}=0.5 \%, \mathrm{C}=1 \%, \mathrm{D}=1.5 \%$ and $\mathrm{E}=2 \%(\mathrm{~W} / \mathrm{W})$

\section{Serum separation of Doogh samples}

Serum separation occurs in fermented milk products due to the aggregation and sedimentation of casein particles during the storage. The use of stabilizers was found necessary to prevent serum separation in fermented milk beverages such as in yogurt drinks (Koksoy and Kilic, 2004). Doogh also is a unstable suspension that needs to be stabilized by stabilizers and additives so in this study when the fermentation by $L$. mesenteroides under condition of sugar existence occurred in Doogh samples, serum separation was reduced compared to that in Doogh without any fermentation process as it has shown in Fig 5. Samples without any fermentation are considered as blank and other samples have investigated in comparison to it. As it has shown in Fig 5 the fermented samples without sugar did not have any significant difference in volume of serum separation however other fermented samples according to enhancement of sugar contents in results, taken from volumes of serum separation, has shown decline appropriately. In 
contrast, the samples containing 1 and 1.5\% sugar have shown insignificantly similar serum separation volumes. Koksoy and Kilic (2004) found reverse correlation between viscosity and serum separation in Ayran samples with adding of stabilizers. Also in this study, we found that fermentation condition including sugar content that have contributed to higher viscosity leads to more prevention of serum separation in Doogh samples. When serum separation volume decreased, the stability of suspension intensified consequently (Thi and Ipsen, 2009). Serum separation volume of fermented sample containing $2 \% \mathrm{w} / \mathrm{w}$ sugar is declined down to $2 \mathrm{ml} 50 \mathrm{ml}^{-1}$.

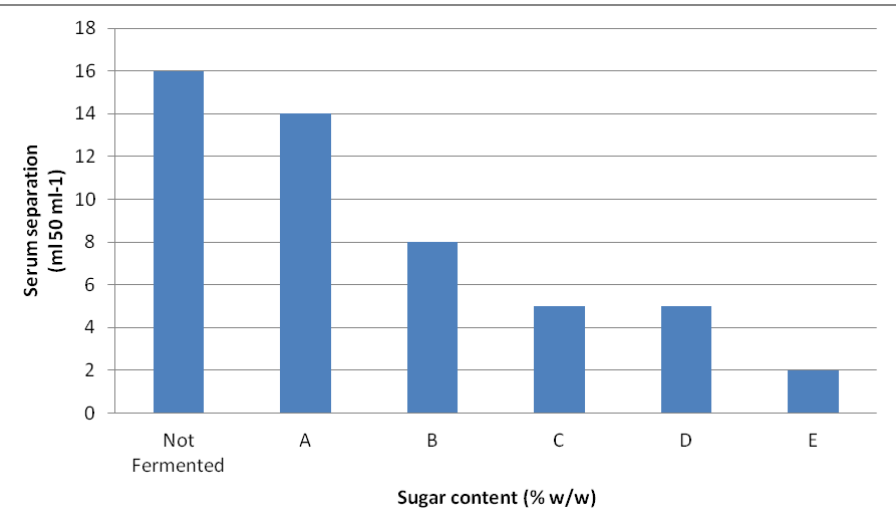

Figure 5 Serum separation of Doogh samples fermented with L. mesenteroide under the optimum conditions of EPS producing, containing different sugar contents including $\mathrm{A}=0 \%, \mathrm{~B}=0.5 \%, \mathrm{C}=1 \%, \mathrm{D}=1.5 \%$ and $\mathrm{E}=2 \%(\mathrm{~W} / \mathrm{W})$ and sample without any fermentation as a sample with original properties, after 15 days storage at $4^{\circ} \mathrm{C}$

\section{Sensory analysis of Doogh samples}

Sensory analysis of samples has shown in table 1 . They statistically analyzed by using Duncan`s multiple comparison test at 5\% confidence level. Panelists did not find any differences in taste of all samples (fermented and unfermented), so it should be resulted that the fermentation process has no effect on taste and odor of the samples and this process can be implemented without any changes in flavor with mentioned conditions, however most of the fermentative processes influence the organoleptic characteristics of substrate (Olanipekun et al., 2009). Produced organic acids affect the taste of the fermented substrate but the range of acidity changes should be considerable (Shene et al., 2008). In Doogh samples, range of changes in titrable acidity of samples was not significant and the results of sensory analysis also have confirmed it. As it has shown in table 1 , consistency and acceptability are significantly different in all groups between samples. Moreover, panelists found less consistency in samples without fermentation and fermented without adding sugar. In the other hand, panelists found other fermented samples more consistence so these results have proved the enhancement of viscosity of fermented samples containing sugar after the 72-h fermentation. Finally, panelists assessed the overall acceptability of samples that the results has shown satisfaction from the fermented Doogh samples in comparison with samples without fermentation and fermented samples without adding sugar. Fermentation with $L$. mesenteroides under optimum conditions of EPS producing, despite less changes in original taste of Doogh have caused to higher satisfactory of panelists in this study that demonstrates acceptability of this method of stabilization to enhance the viscosity of Doogh yogurt drink as an edible suspension

Table 1 Sensory evaluation of Doogh samples containing different sugar contents after 72-h fermentation with L. mesenteroidesunder the optimum conditions of EPS producing and sample without any fermentation as a sample with original properties

\begin{tabular}{lccc}
\hline $\begin{array}{l}\text { Fermentation } \\
\text { sucrose content } \\
(\% \text { w/w }) \text { condition }\end{array}$ & Taste $^{\mathrm{NS}}$ & Consistency & $\begin{array}{c}\text { Overall } \\
\text { acceptability }\end{array}$ \\
\hline Not fermented & 6.4 & $2.6^{\mathrm{a}}$ & $3.9^{\mathrm{a}}$ \\
\hline 0 & 5.7 & $3.1^{\mathrm{b}}$ & $3.2^{\mathrm{b}}$ \\
\hline 0.5 & 5.8 & $5.6^{\mathrm{c}}$ & $5.2^{\mathrm{c}}$ \\
\hline 1 & 6.0 & $5.7^{\mathrm{d}}$ & $4.9^{\mathrm{d}}$ \\
\hline 1.5 & 5.9 & $5.4^{\mathrm{e}}$ & $5.0^{\mathrm{e}}$ \\
\hline 2 & 6.2 & $6.1^{\mathrm{f}}$ & $5.9^{\mathrm{f}}$ \\
\hline
\end{tabular}

Legends: Means at the same column with different superscripts are differen $(P<0.05)$ by Duncan`s multiple comparison test. ${ }^{\text {NS }}$ means Not Significant

\section{CONCLUSION}

Fermentation of Doogh by L. mesenteroides under optimum conditions of EPS producing including $25^{\circ} \mathrm{C}$ temperature, $120 \mathrm{RPM}$ agitation and sugar existence enhance the viscosity of Doogh after 72-h fermentation without any significant changes in the taste and flavor of Doogh. With increase in sugar content up to $2 \%$ w/w, the viscosity of Doogh enhanced appropriately. Enhancement of viscosity in Doogh is confirmed by the results of sensory evaluation, also serum separation volume of fermented Doogh samples have shown decline because of enhancement in viscosity. The viscosity of fermented Doogh sample contained $2 \% \mathrm{w} / \mathrm{w}$ sugar was increased up to $10.01 \mathrm{cp}$ and consequently serum separation

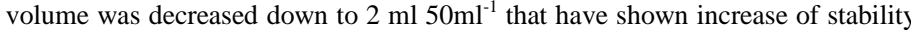
in fermented Doogh samples. Also assessment of consistency in samples by panelists confirmed the viscosity measurements. Finally, this process is known acceptable in experimental and sensory evaluation to intensify the viscosity of Doogh yogurt drink as an edible suspension in addition to its economic benefits in comparison with other stabilization methods based on additives.

Acknowledgement: The authors would like to acknowledge the support provided by "the Research Council of the University of Tehran (Tehran, Iran)" and also "the Research Council of College of Agriculture and Natural Resources of the University of Tehran."

\section{REFERENCES}

ADEBAYO-TAYO, B. C. \& ONILUDE, A. A. 2008. Screening of lactic acid bacteria strains isolated from some Nigerian fermented foods for EPS production. World Applied Sciences Journal, 4, 741-747.

AZARIKIA, F. \& ABBASI, S. 2010. On the stabilization mechanism of Doogh (Iranian yoghurt drink) by gum tragacanth. Food Hydrocolloids, 24, 358-363. http://dx.doi.org/10.1016/j.foodhyd.2009.11.001

BALASWAMY, K., RAO, P., NAGENDER, A. \& SATYANARAYANA, A 2011. Preparation of sour grape (Vitis vinifera) beverages and evaluation of their storage stability. Journal of Food Processing and Technology, 2, 2. http://dx.doi.org/10.4172/2157-7110.1000116

EDEMA, M. O. 2010. Effect of Leuconostoc mesenteroides on the visco-elastic properties of sour maize meal. International Food Research Journal, 17, 55-61. GONZALEZ, N. J., ADHIKARI, K. \& SANCHO-MADRIZ, M. F. 2011 Sensory characteristics of peach-flavored yogurt drinks containing prebiotics and synbiotics. LWT-Food Science and Technology, 44, 158-163. http://dx.doi.org/10.1016/j.lwt.2010.06.008

HEMME, D. \& FOUCAUD-SCHEUNEMANN, C. 2004. Leuconostoc, characteristics, use in dairy technology and prospects in functional foods $\begin{array}{llll}\text { International Dairy } & \text { Journal, } & 14, & 467-494 .\end{array}$ http://dx.doi.org/10.1016/j.idairyj.2003.10.005

HUANG, Q.-L., SIU, K.-C., WANG, W.-Q., CHEUNG, Y.-C. \& WU, J.-Y. 2013. Fractionation, characterization and antioxidant activity of exopolysaccharides from fermentation broth of a Cordyceps sinensis fungus. $\begin{array}{lll}\text { Process Biochemistry, 380-386. } & \text { 48, }\end{array}$ http://dx.doi.org/10.1016/j.procbio.2013.01.001

JOHANNINGSMEIER, S., MCFEETERS, R. F., FLEMING, H. P. \& THOMPSON, R. L. 2007. Effects of Leuconostoc mesenteroides starter culture on fermentation of cabbage with reduced salt concentrations. Journal of food science, 72, M166-M172. http://dx.doi.org/10.1111/j.1750-3841.2007.00372.x

KEKKONEN, R. A., KAJASTO, E., MIETTINEN, M., VECKMAN, V. KORPELA, R. \& JULKUNEN, I. 2008. Probiotic Leuconostoc mesenteroides ssp. cremoris and Streptococcus thermophilus induce IL-12 and IFN- $\gamma$ production. World Journal of Gastroenterology, 14, 1192 http://dx.doi.org/10.3748/wjg.14.1192

KIANI, H., MOUSAVI, M., RAZAVI, H. \& MORRIS, E. 2010. Effect of gellan, alone and in combination with high-methoxy pectin, on the structure and stability of Doogh, a yogurt-based Iranian drink. Food Hydrocolloids, 24, 744-754 http://dx.doi.org/10.1016/j.foodhyd.2010.03.016

KOKSOY, A. \& KILIC, M. 2004. Use of hydrocolloids in textural stabilization of a yoghurt drink, ayran. Food hydrocolloids, 18, 593-600. http://dx.doi.org/10.1016/i.foodhyd.2003.10.002

KUNDA, P. B., BENAVENTE, F., CATALÁ-CLARIANA, S., GIMÉNEZ, E. BARBOSA, J. \& SANZ-NEBOT, V. 2012. Identification of bioactive peptides in a functional yogurt by micro liquid chromatography time-of-flight mass spectrometry assisted by retention time prediction. Journal of Chromatography A, 1229, 121-128. http://dx.doi.org/10.1016/j.chroma.2011.12.093

LAURENT, M. \& BOULENGUER, P. 2003. Stabilization mechanism of acid dairy drinks (ADD) induced by pectin. Food Hydrocolloids, 17, 445-454 http://dx.doi.org/10.1016/S0268-005X(03)00028-6

NAESSENS, M., CERDOBBEL, A., SOETAERT, W. \& VANDAMME, E. J. 2005. Leuconostoc dextransucrase and dextran: production, properties and applications. Journal of Chemical Technology and Biotechnology, 80, 845-860 http://dx.doi.org/10.1002/jctb.1322

O'CONNELL, J. \& FOX, P. 2001. Significance and applications of phenolic compounds in the production and quality of milk and dairy products: a review. International Dairy Journal, 11, 103-120. http://dx.doi.org/10.1016/S0958 6946(01)00033-4

OLANIPEKUN, B., OTUNOLA, E., ADELAKUN, O. \& OYELADE, O. 2009 Effect of fermentation with Rhizopus oligosporus on some physico-chemical 
properties of starch extracts from soybean flour. Food and chemical toxicology, 47, 1401-1405. http://dx.doi.org/10.1016/j.fct.2009.02.023

PARK, Y. 1994. Nutrient and mineral composition of commercial US goat milk yogurts. Small Ruminant Research, 13, 63-70. http://dx.doi.org/10.1016/0921 4488(94)90032-9

RAMÍREZ-SUCRE, M. O. \& VÉLEZ-RUIZ, J. F. 2013. Physicochemical, rheological and stability characterization of a caramel flavored yogurt. $L W T$ Food Science and Technology, 51, 233-241. http://dx.doi.org/10.1016/j.lwt.2012.09.014

RUAS-MADIEDO, P., HUGENHOLTZ, J. \& ZOON, P. 2002. An overview of the functionality of exopolysaccharides produced by lactic acid bacteria International Dairy Journal, 12, 163-171. http://dx.doi.org/10.1016/S09586946(01)00160-1

SANTOS, M., TEIXEIRA, J. \& RODRIGUES, A. 2000. Production of dextransucrase, dextran and fructose from sucrose using Leuconostoc mesenteroides NRRL B512 (f). Biochemical Engineering Journal, 4, 177-188. http://dx.doi.org/10.1016/S1369-703X(99)00047-9

SEFA-DEDEH, S., CORNELIUS, B. \& OHENE AFOAKWA, E. 2003. Effect of fermentation on the quality characteristics of nixtamalized corn. Food research international, 36, 57-64. http://dx.doi.org/10.1016/S0963-9969(02)00108-4

SHENE, C., CANQUIL, N., BRAVO, S. \& RUBILAR, M. 2008. Production of the exopolysacchzrides by Streptococcus thermophilus: Effect of growth conditions on fermentation kinetics and intrinsic viscosity. International journal $\begin{array}{llll}\text { of food microbiology, } & 124, & 279-284\end{array}$ http://dx.doi.org/10.1016/j.ijfoodmicro.2008.03.013

THI, A. D. P. \& IPSEN, R. 2009. Stabilization of acidified milk drinks using pectin. Asian Journal of Food and Agro-Industry, 2, 155-165. 